\title{
Mentor-mentee Relationship: A Win-Win Contract In Graduate Medical Education
}

\author{
Hale Z. Toklu ${ }^{1}$, Jacklyn C. Fuller ${ }^{2}$ \\ 1. Graduate Medical Education, HCA/UCF North Florida Division 2. GME, Ocala Regional Medical Center/ \\ University of Central Florida College of Medicine
}

$\square$ Corresponding author: Hale Z. Toklu, haletoklu@yahoo.com

Disclosures can be found in Additional Information at the end of the article

\section{Abstract}

Scholarly activities (i.e., the discovery of new knowledge; development of new technologies, methods, materials, or uses; integration of knowledge leading to new understanding) are intended to measure the quality and quantity of dissemination of knowledge. A successful mentorship program is necessary during residency to help residents achieve the six core competencies (patient care, medical knowledge, practice-based learning and improvement, systems-based practice, professionalism, interpersonal and communication skills) required by the Accreditation Council for Graduate Medical Education (ACGME). The role of the mentor in this process is pivotal in the advancement of the residents' knowledge about evidence-based medicine. With this process, while mentees become more self-regulated, exhibit confidence in their performance, and demonstrate more insight and aptitude in their jobs, mentors also achieve elevated higher self-esteem, enhanced leadership skills, and personal gratification. As such, we may conclude that mentoring is a two-sided relationship; i.e., a 'win-win' style of commitment between the mentor and mentee. Hence, both parties will eventually advance academically, as well as professionally.

Received 11/16/2017

Review began 11/28/2017

Review ended 11/29/2017

Published 12/05/2017

C) Copyright 2017

Toklu et al. This is an open access article distributed under the terms of the Creative Commons Attribution License CC-BY 3.0., which permits unrestricted use, distribution, and reproduction in any medium, provided the original author and source are credited.
Categories: Medical Education, Miscellaneous, Quality Improvement

Keywords: resident training, scholarly activity, mentorship, mentor, advisor, medical resident, graduate medical education, internship and residency, residency, clinical training

\section{Editorial}

Introduction

In Greek mythology, as told in Homer's Odyssey, Mentor was a loyal friend and adviser to the King of Ithaca, Odysseus. When Odysseus left for the Trojan War, Mentor raised Odysseus' son, Telemachus, and prepared him to be the king. While doing this, Mentor encouraged Telemachus to take a journey. Athena, the Goddess of Wisdom, took the shape of Mentor and accompanied Telemachus during his journey to Pylos and Sparta [1].

Today, the terms 'advisor' and 'mentor' are often used synonymously. Although similar, they refer to different concepts. Advisor is a person who gives advice in a particular field based on their expertise, while a mentor is an experienced and trusted adviser. A few examples of famous mentor-mentee relationships in history are Plato mentor to Aristotle, Aristotle mentor to Alexander the Great, and Sigmund Freud mentor to Carl Jung.

As the moral of the anonymous tale of Rabbit's $\mathrm{PhD}$ thesis goes, it could be argued that your mentor matters rather than your thesis subject (the anecdote is available on 
Docere is a Latin word first introduced by Cicero in his book De Oratore. The term means to instruct, teach, advice and also refers to the learned person i.e., the scholar. The word doctor originated from 'docere'. Thus, teaching and shaping medical students, residents, and fellows are essential roles of a physician [2]. Even though the distinction between advisor and mentor is not clear in most programs, the difference between the roles of advisor and mentor is of critical importance. As the roles get clear, the expectations and satisfaction rates improve [3].

Scholarly activities are intended to measure the quality and quantity of dissemination of knowledge. The role of mentors in this process is crucial in terms of spreading evidence-based medicine [4].

The metrics may vary among programs and institutions; however, publishing journal articles, presenting in meetings and delivering lectures are commonly accepted scholarly activities [2]. External funding and citations are additional measures of these activities.

When the medical jungle is taken into consideration, guiding medical residents as mentors is crucial. Effective mentorship helps the residents develop the six core competencies (patient care, medical knowledge, practice-based learning, systems-based practice, professionalism, and communication skills) required by Accreditation Council for Graduate Medical Education (ACGME).

Mentoring residents is an inevitable task of a clinician educator in academic medicine. It is a two-sided relationship which increases visibility within the medical community when appropriately established. It is a key factor in helping to promote scholarly activities as well as scholarly productivity as a whole. This 'win-win' style of commitment-mentorship, between the mentor and mentee, will eventually advance both parties academically as well as professionally. In addition to the knowledge and experience gained by both participants, mentees become more self-regulated, exhibit confidence in their performance, and demonstrate more insight and aptitude in their jobs. On the other hand, mentors achieve elevated higher self-esteem, enhanced leadership skills, and personal gratification.

The roles and qualities of the mentor and mentee are summarized in Table 1. 


\section{Cureus}

\section{Mentor}

- Active teaching

- Hearing

- Pointing to the gold mine

- Showing the path

- Probing to raise the bar

- Being a role model

- Respect

- Focus

- Empathy

- Devoting time

- Door opener/Problem solver

- Inspires trust

- Does the right thing

- Promotes ideas

- Motivates/Inspires

- Carves new roads

- Thinks long term - the end goal

- Charts new growth

\section{Mentee}

- Active learning

- Listening

- Digging the gold mine

- Taking the path

- Dedication to raise the bar

- Mirroring the role model

- Respect

- Focus

- Empathy

- Devoting time

- Cooperate to solve problems

- Develops trust

- Do things right

- Adapts ideas

- Motivates/Inspires

- Follow the map

- Meets the expectations

- Adapts growing

\section{TABLE 1: The roles and qualities of the mentor and mentee}

As with other developmental processes, mentoring also has a life cycle which moves from the initiation phase where the mentor and mentee get to know each other and set expectations, to the final phase when the mentoring relationship has achieved its mission, and both participants have mutually agreed to function independently (Figure 1). The length of each phase depends on the interaction and dynamics related to the readiness, enthusiasm, and devotion of both the mentor and the mentee.
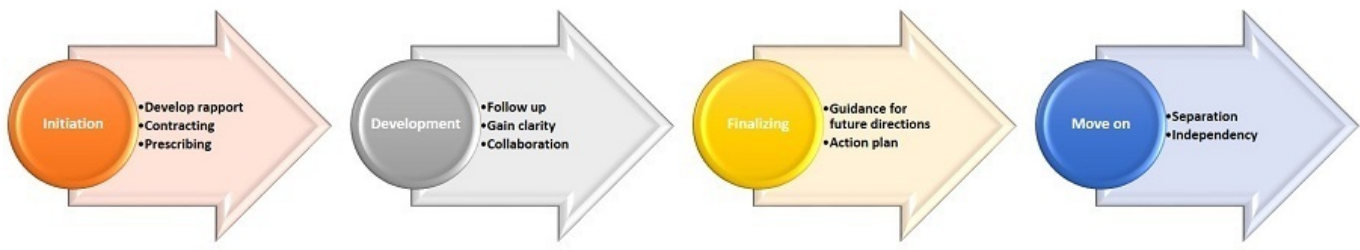


\section{FIGURE 1: Phases of the relationship between the mentor and mentee}

Although mentorship has been in existence for centuries, the influx of current data documented in the literature has created a sense of urgency among graduate medical education programs and institutions to establish a system in which residents are paired with official mentors. Several studies showed its effectiveness in integrating clinical, professional, and academic development on an individualized basis [3, 5]. The feedback and guidance are highly appreciated by trainees because of the comprehensive approach to personal interests, skills, and competencies.

It is evident that the success of a resident's scholarly productivity is highly contingent on the synergy developed between the mentor and mentee. Students' feedback indicates that a longterm commitment between the mentor and the mentee positively outweighs an individual encounter [5].

Conclusion

The implementation of a successful mentorship program is an effective strategy for creating an environment which will promote scholarly activities among residents in terms of quality and quantity. Both mentors and mentees will significantly benefit from exchanging ideas and sharing knowledge, as well as personal growth and professional development. Additionally, academic institutions will benefit from creating a culture that supports and promotes scholarship via an effective mentorship program.

\section{Additional Information}

\section{Disclosures}

Conflicts of interest: In compliance with the ICMJE uniform disclosure form, all authors declare the following: Payment/services info: All authors have declared that no financial support was received from any organization for the submitted work. Financial relationships: All authors have declared that they have no financial relationships at present or within the previous three years with any organizations that might have an interest in the submitted work. Other relationships: All authors have declared that there are no other relationships or activities that could appear to have influenced the submitted work.

\section{Acknowledgements}

Both authors contributed to planning, literature research and writing equally. Therefore, they have equal correspondence.

\section{References}

1. Roberts A, Chernopiskaya A: A historical account to consider the origins and associations of the term mentor. History of Education Society Bulletin. 1999, 64:81-90.

2. Grady EC, Roise A, Barr D, et al.: Defining scholarly activity in graduate medical education . J Grad Med Educ. 2012, 4:558-61. 10.4300/JGME-D-12-00266.1

3. Woods SK, Burgess L, Kaminetzky C, McNeill D, Pinheiro S, Heflin MT: Defining the roles of advisors and mentors in postgraduate medical education: faculty perceptions, roles, responsibilities, and resource needs. J Grad Med Educ. 2010, 2:195-200. 10.4300/JGME-D-0900089.1 
Cureus

4. Boyer EL: Scholarship Reconsidered: Priorities of the Professoriate. Carnegie Foundation for the Advancement of Teaching, New Jersey; 1990.

5. Collins K, Oliver SW: Mentoring: what matters most?. Clin Teach. 2017, 14:298-300.

10.1111/tct.12602 